\title{
Change in duration of elevated concentrations of melatonin is the major factor in photoperiod response of the tammar, Macropus eugenii
}

\author{
S. J. McConnell*, C. H. Tyndale-Biscoe and L. A. Hinds \\ Division of Wildlife and Rangelands Research, CSIRO, P.O. Box 84 Lyneham, A.C.T. 2602, \\ Australia
}

\begin{abstract}
Summary. In Exp. 1, 10 quiescent non-lactating tammars were exposed to $15 \mathrm{~L}: 9 \mathrm{D}$ (Days -41 to -1 ), 24L:0D (Days 0 to 14 ), 15L:9D (Days 15 to 34 ) and then to ambient increasing daylength from 13L:11D on Day 35. From Days 0 to 22 they received a s.c. injection of melatonin $(400 \mathrm{ng} / \mathrm{kg}, \mathrm{N}=5)$ or the arachis oil vehicle $(\mathrm{N}=5)$ in the evening $(19: 30 \mathrm{~h}) 2.5 \mathrm{~h}$ before dark. Exposure to $24 \mathrm{~L}: 0 \mathrm{D}$ abolished the nocturnal plasma melatonin rise but this was reinstated by subsequent exposure to 15L:9D. Of 5 melatonin-treated tammars, 4 gave birth on Day 45, so had failed to respond to the melatonin injection alone but reactivated when this was combined with the endogenous melatonin rise during exposure to $15 \mathrm{~L}: 9 \mathrm{D}$. Of 5 control tammars, 4 remained quiescent until reactivated by the decrease in daylength to $13 \mathrm{~L}: 11 \mathrm{D}$, and gave birth significantly later (Day 63.7 $\pm 2 \cdot 2$, mean \pm s.e.m., $P<0.05$ ). In Exp. 2, 6 tammars were exposed to 15L:9D (Days -15 to -1 ) and then to 12L:12D (Days 0 to 15 ) by extending the dark phase by $3 \mathrm{~h}$ in the morning. This extended the nocturnal melatonin rise by $2-3 \mathrm{~h}$ in the morning and all 6 tammars gave birth on Day $31 \cdot 2 \pm 1.0$. A transient pulse of peripheral plasma prolactin $(81.5 \pm 31.0 \mathrm{ng} / \mathrm{ml})$ was detected at dawn during 15L:9D in all 6 tammars but was not observed in any of them 5 days after exposure to $12 \mathrm{~L}: 12 \mathrm{D}$. Together these results do not support the time of day hypothesis but indicate that increase in duration of the nocturnal melatonin rise mediates the effects of decreased daylength on reactivation of the corpus luteum, and that the first detectable result of this may be the abolition of a transient prolactin pulse at the end of the dark phase.
\end{abstract}

\section{Introduction}

It is now clearly established that the pineal gland through its hormone, melatonin, mediates the effects of photoperiod on reproduction in several seasonally breeding mammals. There is a circadian rhythm in the synthesis and secretion of melatonin by the pineal, with a peak during the dark phase, and it has been suggested that different components of this nocturnal rise, such as amplitude, duration and phase, provide the photoperiodic information (see Lincoln, Almeida \& Arendt, 1981; Goldman \& Darrow, 1983; Karsch et al., 1984; Tamarkin, Baird \& Almeida, 1985). In some species of mammal, such as the Syrian hamster (Tamarkin, Westrom, Hamill \& Goldman, 1976; Stetson \& Tay, 1983) and the white-footed mouse (Margolis \& Lynch, 1981) the response is thought to be due to exposure to melatonin during a sensitive phase each $24-\mathrm{h}$ period, because the photoperiod response can be mimicked by exposure to melatonin at a particular time of day. For other species, such as the sheep and Djungarian hamster, the total duration of elevated melatonin

* Present address: Division of Animal Production, CSIRO, P.O. Box 239, Blacktown, New South Wales, 2148, Australia. 
concentration experienced each day is the critical factor (Bittman \& Karsch, 1984; Goldman, Darrow \& Yogev, 1984). In pinealectomized sheep and Djungarian hamsters daily infusions of melatonin for periods equivalent to the dark phases of long or short photoperiods elicit the same reproductive responses as in pineal-intact animals exposed to these photoperiods alone (Carter \& Goldman, 1983a, b; Bittman, Dempsey \& Karsh, 1983; Bittman \& Karsch, 1984; Yellon et al., 1985).

The tammar wallaby, Macropus eugenii, a marsupial that lives in temperate zones of Australia, has a marked seasonal breeding pattern with the majority of females giving birth 6 weeks after the austral summer solstice. The seasonality is controlled by an unusual mechanism which involves the tonic inhibition by the pituitary of the corpus luteum (CL) of post-partum ovulation and of the associated embryo for up to 11 months (Berger, 1966). Prolactin has been suggested as the agent of pituitary inhibition (Tyndale-Biscoe \& Hawkins, 1977), acting directly on the CL (Sernia \& Tyndale-Biscoe, 1979), but the changes in peripheral plasma concentrations of prolactin that are predicted by this hypothesis have not so far been demonstrated (Hinds \& den Ottolander, 1983; Tyndale-Biscoe \& Hinds, 1984).

Environmental factors are also involved; during the period of declining daylength the sucking stimulus of the pouch young is the proximate factor and this condition is termed lactational quiescence. During this period removal of the pouch young results in birth 26-27 days later (Merchant, 1979). After the winter solstice removal of the pouch young does not lead to reactivation. The proximate factor is a component of increasing daylength and this condition is termed seasonal quiescence. Reactivation of the CL and blastocyst occurs naturally after the summer solstice in December. Reactivation has been induced experimentally before this time by a decrease in daylength of $3 \mathrm{~h}$ from 15L:9D to 12L:12D (Sadleir \& Tyndale-Biscoe, 1977; Hinds \& den Ottolander, 1983), when birth and post-partum oestrus occurred 32-33 days later. This is 6 days longer than the interval from removing the pouch young during lactational quiescence (Merchant, 1979) and it was suggested that the longer interval might reflect the time required for the nocturnal elevation of plasma melatonin to respond to the longer dark period. However, McConnell \& Tyndale-Biscoe (1985) demonstrated that the daily plasma melatonin profile changed rapidly in response to this photoperiod change, even though birth occurred $32 \pm 0.4$ days later. The same response was observed when tammars, exposed to the inhibitory photoperiod of $15 \mathrm{~L}: 9 \mathrm{D}$, were given melatonin at 19:30 h, $2.5 \mathrm{~h}$ before lights off, thus extending the total duration of elevated melatonin concentration to about $11.5 \mathrm{~h}$. These results showed that elevated melatonin provides a potent signal in the tammar's response to photoperiod but they did not resolve whether the signal was the exposure to melatonin at a sensitive period in the evening or was because the exogenous and endogenous melatonin were summated and interpreted as an increase in the total duration of the nocturnal elevation of melatonin. The present study was designed to discriminate between these alternatives by testing the response of tammars to evening melatonin injections alone, or to an extension of the endogenous nocturnal melatonin rise by prolonging the dark phase in the morning instead of the evening.

We also report the first evidence for the way in which prolactin may play its part in the sequence from photoperiod change to reactivation of the CL.

\section{Materials and Methods}

\section{Animals}

Post-lactating tammars were taken from the colony maintained at the Division of Wildlife and Rangelands Research, Canberra, in August (Exp. 1) or November (Exp. 2), during the period of increasing daylength, when they were in seasonal quiescence. Throughout the study they were maintained on a diet of pelleted lucerne chaff and oats, supplemented with fresh carrots and apples, and water ad libitum. 
Experiment 1. Ten tammars were housed in 3 pens (each $1.8 \times 1.85 \mathrm{~m}$ ) under controlled temperature $\left(24 \pm 2^{\circ} \mathrm{C}\right)$ and illumination. Light was provided by four Osram Daylight fluorescent tubes which provided $4325 \mathrm{~cd} \mathrm{~m}^{-2}$ in the pens. A $15-\mathrm{W}$ red pilot lamp provided low illumination during the dark phases. All the tammars were first exposed to an inhibitory photoperiod of $15 \mathrm{~h}$ light:9 h dark (15L:9D) for 6 weeks (Days -41 to -1 ). On Day 0 they were exposed to continuous light (24L:0D) for 14 days to abolish the endogenous melatonin rise, and then returned to 15L:9D (Days 15-34). During the first and last periods the lights went on at 07:00 h each day. On Day 35 all the tammars were returned to outside pens which were about 13L:11D and thereafter experienced ambient increasing daylength and temperature (Fig. 2a). The tammars were randomly assigned to one of two groups and from Days 0 to 22 at 19:30 h the melatonin-treated group $(N=5)$ received a daily subcutaneous injection of melatonin (Sigma Chemical Co., St Louis, MO, U.S.A., $400 \mathrm{ng} / \mathrm{kg}$ body weight) in arachis oil, and the control group $(\mathrm{N}=5)$ received the arachis oil alone. Sexually mature males were run with the females from Day -15 to Day -1 and then continuously from Day 26. The females were checked for a new young in the pouch and a copulatory plug in the urogenital sinus, indicative of oestrus, every 1-3 days from Day -14 to Day -2 and then daily from Day 27.

Experiment 2. Six tammars were exposed to a photoregimen of 15L:9D (Days -15 to -1 ) then 12L:12D (Days 0 to 15) (Fig. 2b). The lights were turned off at 22:00 h each day so that during the second photoperiod they experienced an extension of the dark phase by $3 \mathrm{~h}$ in the morning, instead of the evening as in the previously published experiments of Hinds \& den Ottolander (1983) and McConnell \& Tyndale-Biscoe (1985). On Day 25 they were returned to outside pens with sexually mature males and daily checks for birth and oestrus began on Day 26.

Blood samples. Blood samples $(2.5 \mathrm{ml})$ were obtained from the lateral tail vein of the tammars as previously described (McConnell \& Tyndale-Biscoe, 1985). In Exp. 1 samples were taken for plasma melatonin at intervals of $2-7 \mathrm{~h}$ for up to $22 \mathrm{~h}$ under each of the photoperiods on Day 14 (24L:0D) and Day 22 (15L:9D). In Exp. 2 samples for melatonin and prolactin were taken at intervals of $1-3.5 \mathrm{~h}$ for $20 \mathrm{~h}$ during each of the photoperiods on Day -4 (15L:9D) and Day 5 (12L:12D). For each sample the tammars were caught and restrained briefly in hessian sacks before being released. Aliquants of plasma were stored separately at $-20^{\circ} \mathrm{C}$ for the assay of each hormone.

\section{Hormone assays}

Prolactin. The concentration of prolactin in plasma was determined using the heterologous radioimmunoassay of McNeilly \& Friesen (1978) validated for the tammar by Hinds \& TyndaleBiscoe (1982). The antiserum (33/1-8) was raised against human prolactin in a guinea-pig by $\mathrm{Dr}$ A. S. McNeilly, Edinburgh, and the standard was ovine prolactin, NIH-P-S12. The sensitivity of the assay was $2 \mathrm{ng} / \mathrm{ml}$ and intra- and inter-assay coefficients of variation were 8 and $12 \%$ respectively. The recovery of a range of concentrations of prolactin added to tammar plasma closely correlated with the actual amount added $(r=0.998, P<0.001)$ and was always within $12 \%$ of the expected value. All samples from individual animals were analysed within one assay.

Direct radioimmunoassay for melatonin. Melatonin was measured using a modification of the radioimmunoassay of Kennaway, Gilmore \& Seamark (1982a) which has been previously validated for the tammar (McConnell \& Tyndale-Biscoe, 1985). The source and cross-reactivities of the antiserum (G 280) have already been described (Kennaway et al., 1982a). In this study melatonin was measured directly in plasma; deletion of the solvent extraction step allowed for a more rapid assay and enabled the volume of plasma used to be halved. These modifications are of considerable advantage when multiple sequential samples must be taken (see Webley, Mehl \& Willey, 1985). However, haemolysis in samples and plasma effects of individual tammars did interfere, and additional control steps were required. The modified assay procedure is outlined below. 
Aliquants of $500 \mu \mathrm{l}$ plasma (in duplicate) were taken for each sample. Each tube received $500 \mu \mathrm{l}$ buffer (BSA-PO ${ }_{4}, \mathrm{pH} 7 \cdot 4$ ), $100 \mu \mathrm{l}\left[{ }^{3} \mathrm{H}\right]$ melatonin (sp. act. $30 \cdot 4 \mathrm{Ci} / \mathrm{mmol}, 10000$ c.p.m.: New England Nuclear Corp., Boston, MA, U.S.A.) and $100 \mu \mathrm{l}$ antiserum (1:5000). After incubation $(>4 \mathrm{~h})$ at $4{ }^{\circ} \mathrm{C}$ the bound and unbound radioligand were separated by the addition of $200 \mu \mathrm{l}$ dextran-coated charcoal solution $(0.625 \%)$ for $30 \mathrm{~min}$ and then centrifuged. Aliquants $(1 \mathrm{ml})$ of the supernatant were taken for determination of the radioactivity in a liquid scintillation counter. A series of melatonin standards (0-1000 pg in triplicate) in buffer was treated similarly.

At a final dilution of 1:60000 the antiserum bound $30 \%$ of the $\left[{ }^{3} \mathrm{H}\right]$ melatonin. Sensitivity of the assay (lowest standard displaced more than 2 standard deviations from the zero standard) was $7.8 \mathrm{pg} /$ tube. Non-specific binding in buffer was $1.0 \pm 0.2 \%$ (mean \pm s.e.m., $n=3$ ) and in plasma $2 \cdot 1 \pm 0.1 \%(n=10)$. The intra- and inter-assay coefficients of variation were 8.4 and $17.9 \%$ respectively, determined from samples of a common plasma pool $(\simeq 80 \mathrm{pg} / \mathrm{ml})$ in 6 assays.

After correction for the plasma effect (see below), all tubes were expressed as LOGIT and the melatonin concentrations in the plasma samples were determined by reference to the standard curve.

Parallelism of dose-response curves and plasma effects. Two series of melatonin standards $(7 \cdot 8-500 \mathrm{pg})$ in triplicate were set up in assay buffer, or in plasma from a pinealectomized tammar and buffer $(1: 1)$. Aliquants $(200-1000 \mu \mathrm{l})$ of plasma were taken from a pinealectomized tammar, and from an intact tammar during the night, and from the supernatant of a tammar pineal homogenized in buffer, and each was made up to volume $(1000 \mu \mathrm{l})$ with buffer. All were assayed directly as described and the displacement curves obtained from the pinealectomized plasma with melatonin standards, night-time plasma and pineal gland extract were parallel to the buffer standard curve

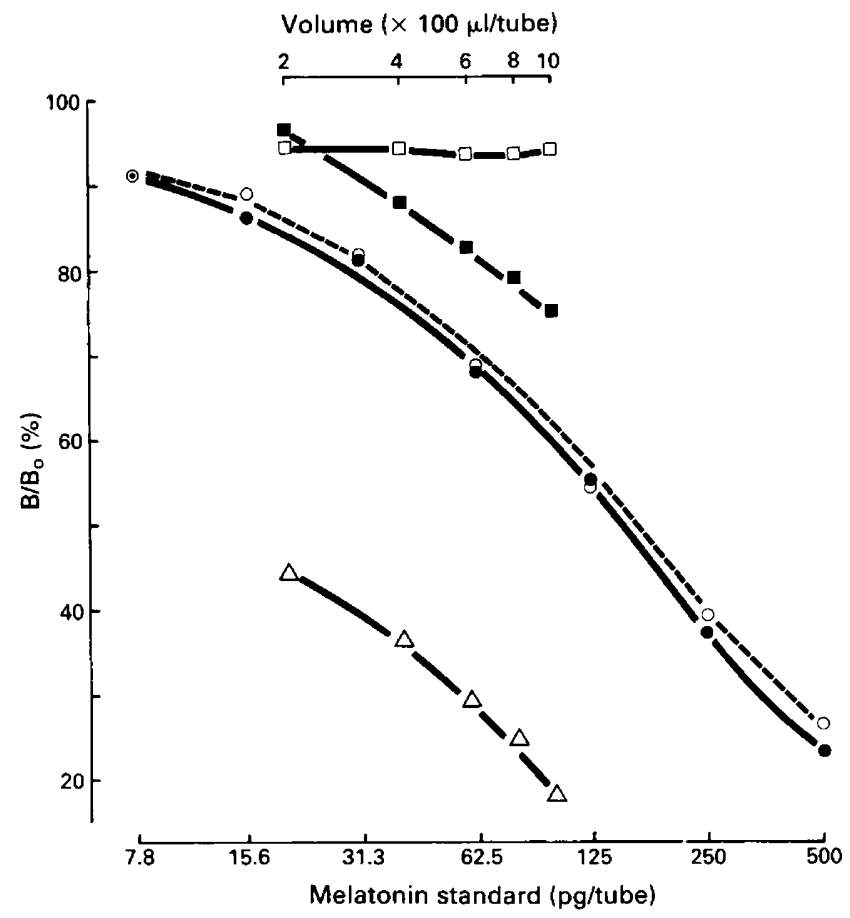

Fig. 1. The dose-response curves for melatonin added to assay buffer $(\bullet)$, pinealectomized tammar plasma $(\bigcirc)$, dilutions of an homogenate of tammar pineal gland $(\triangle)$, plasma taken from an intact tammar during the night ( $\boldsymbol{C})$ and plasma from a pinealectomized tammar $(\square)$. $\mathrm{B}=$ amount of $\left[{ }^{3} \mathrm{H}\right]$ melatonin bound in the presence of unlabelled hormone; $\mathbf{B}_{0}=$ amount of $\left[{ }^{3} \mathrm{H}\right]$ melatonin bound in the absence of unlabelled hormone. 
Table 1. Intervals (days) to birth and oestrus in tammars given a daily injection of melatonin or the oil vehicle in the evening before exposure to decrease in photoperiod

\begin{tabular}{|c|c|c|c|c|}
\hline \multirow{2}{*}{$\begin{array}{l}\text { Pretreatment } \\
\text { (Days 0-22) }\end{array}$} & \multicolumn{2}{|c|}{$\begin{array}{l}\text { Interval from start } \\
\text { of pretreatment to: }\end{array}$} & \multicolumn{2}{|c|}{$\begin{array}{l}\text { Interval to birth/oestrus } \\
\text { after photoperiod change to: }\end{array}$} \\
\hline & Birth & Oestrus & 15L:9D & 13L:11D \\
\hline $\begin{array}{l}\text { Arachis oil* } \\
\text { Melatonin }\end{array}$ & $\begin{array}{l}{ }^{2} 63 \cdot 7 \pm 2 \cdot 2(3) \\
b_{4} 45 \cdot 0 \pm 0(4)\end{array}$ & $\begin{array}{l}{ }^{\mathrm{a}} 63 \cdot 0 \pm 1 \cdot 7(4) \\
\mathrm{b} 45 \cdot 0 \pm 0(4)\end{array}$ & $\begin{array}{l}\mathrm{b} 48 \cdot 0 \pm 1 \cdot 7(4) \\
\mathrm{c} 30 \cdot 0 \pm 0(4)\end{array}$ & $\begin{aligned} c 28 \cdot 0 & \pm 1 \cdot 7(4) \\
10 \cdot 0 & \pm 0(4)\end{aligned}$ \\
\hline
\end{tabular}

Values are the mean \pm s.e.m. for the number of animals in parentheses.

Within and between columns, means with the same superscripts are not significantly different $(P>0.05$, Student's $t$ test).

* Analyses exclude 1 tammar that gave birth on Day 37 and one that did not give birth or show oestrus.

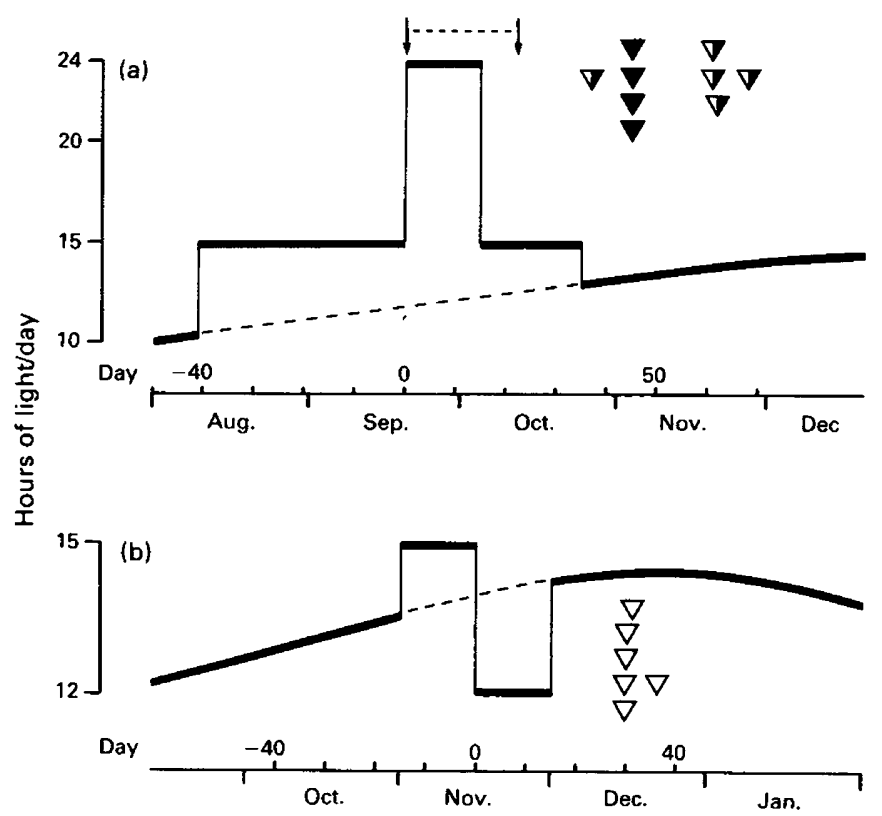

Fig. 2. The protocols and results of Exps 1 \& 2. In Exp. 1 (a), non-lactating quiescent tammars were exposed to a photoregimen of 15L:9D, 24L:0D, 15L:9D then 13L:11D. Each day from Day 0 to 22 they received an injection of melatonin $(400 \mathrm{ng} / \mathrm{kg}$ body weight) or the oil vehicle in the evening $(\downarrow)$. Birth and/or oestrus is indicated for each melatonin-treated $(\nabla)$ and oil-treated $(\nabla)$ tammar. In Exp. 2 (b), a separate group of non-lactating quiescent tammars were exposed to a photoregimen of 15L:9D then $12 \mathrm{~L}: 12 \mathrm{D}$ by extending the dark phase in the morning. The resulting birth and/or oestrus are indicated $(\nabla)$.

(Fig. 1). These results demonstrate that the melatonin standard and the endogenous hormone in the plasma and buffer medium behaved identically in the assay, and that factors in tammar plasma did not affect the dose-response. However, the binding of the radioligand in the absence of melatonin standard $\left(\mathbf{B} / \mathbf{B}_{0}\right)$ was highly variable in the plasma of individual tammars. Expressing $\mathbf{B}_{0}$ of buffer as $100 \%$, the $\mathrm{B}_{0}$ of plasma:buffer (1:1), using the plasma of individual tammars, ranged from 98.8 to $116 \cdot 3 \%(107 \cdot 8 \pm 6 \cdot 1$, mean \pm s.d., $n=11)$. The plasma effect for each tammar was calculated using its own charcoal-stripped plasma and was corrected for before determining the melatonin concentrations. The plasma was stripped by adding $200 \mu \mathrm{l} 0.625 \%$ dextran-coated charcoal to $1200 \mu \mathrm{l}$ plasma and incubating for $30 \mathrm{~min}$ at room temperature. No displacement of the radioligand 
occurred after the addition of increasing volumes of pinealectomized tammar plasma to the buffer (Fig. 1), so we conclude that the endogenous hormone being measured in the assay is of pineal origin.

The effect of haemolysis of plasma samples was assessed by the addition of radioligand to normal and haemolysed plasma obtained from the same blood pool. Haemolysis was achieved by physical damage to the erythrocytes. From each plasma sample, $1 \mathrm{ml}$ in duplicate, containing $\simeq 10000$ c.p.m. $\left[{ }^{3} \mathrm{H}\right]$ melatonin, was added to $10 \mathrm{ml}$ scintilation fluid. The radioactivity in the haemolysed plasma was calculated as $77 \%$ of that in the normal plasma and so to avoid overestimation of the melatonin concentration haemolysed samples were excluded.

Recovery of exogenous melatonin. The recovery of exogenous melatonin from tammar plasma was determined by the addition of melatonin standards $(4-1000 \mathrm{pg} / \mathrm{ml})$ in triplicate to $500 \mu \mathrm{l}$ aliquants of plasma from a pinealectomized tammar or to buffer. All tubes received another $500 \mu l$ buffer and were assayed as described. After correcting for the plasma effect the amount of melatonin added to the plasma was determined by reference to the buffer standards. The regression equation for melatonin added $(x)$ plotted against melatonin measured $(y)$ was $y=0.99 x-3.53$ with $r=0.997$. These results show that the assay was able to measure accurately the melatonin concentrations in a plasma medium.

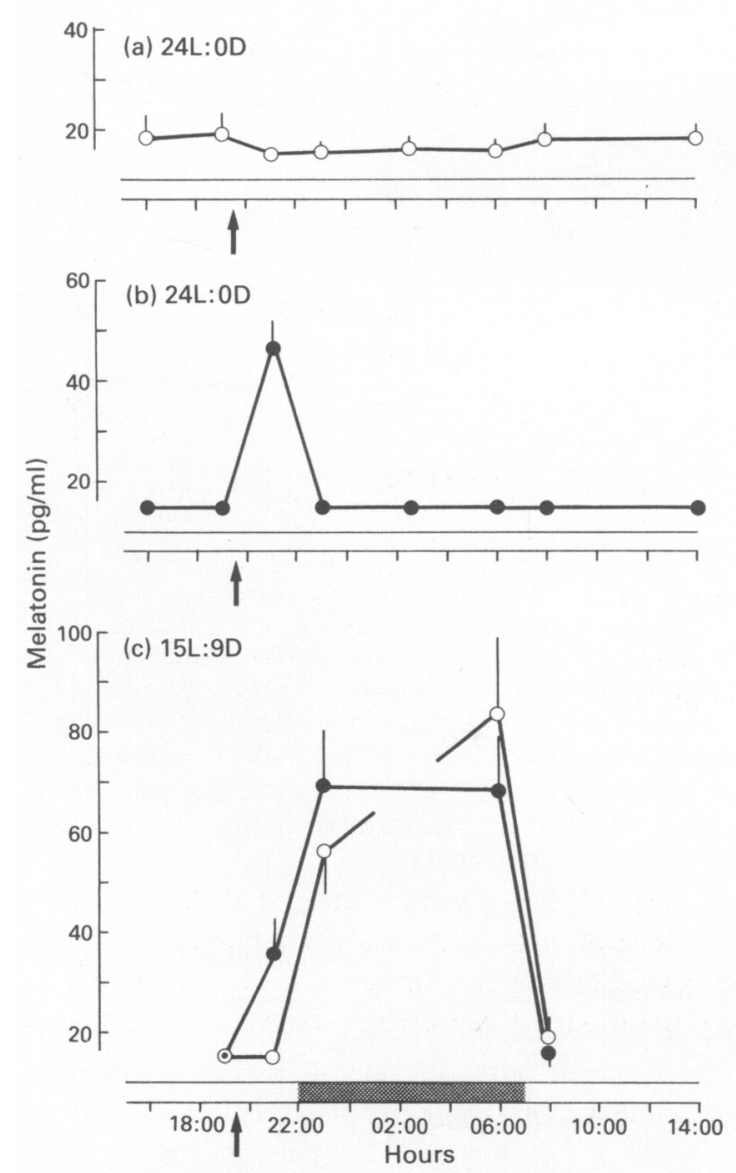

Fig. 3. Plasma melatonin concentrations (mean \pm s.e.m.) of tammars in Exp. 1 during exposure to $24 \mathrm{~L}: 0 \mathrm{D}(\mathrm{a}, \mathrm{b})$ and subsequently to $15 \mathrm{~L}: 9 \mathrm{D}(\mathrm{c})$. The tammars were injected with $400 \mathrm{ng}$ melatonin $/ \mathrm{kg}(\odot)$ or the arachis oil vehicle $(O)$ at $19: 30 \mathrm{~h}(\uparrow)$. 


\section{Results}

\section{Experiment 1}

Of the 5 tammars in the control group one gave birth on Day 37 and 4 gave birth or came into oestrus between Days 61 and 68 ( $63 \pm 1 \cdot 7$, mean \pm s.e.m.), 28 days after the change from 15L:9D to 13L:11D (Table 1). In the melatonin-treated group, however, 4 tammars gave birth and showed oestrus on Day 45, or 30 days after the change from 24L:0D to 15L:9D (Table 1, Fig. 2a), while the 5 th failed to give birth or display oestrus during the experiment. These intervals to birth/oestrus from the start of injections were significantly different between the two groups $(P<0.005$, Student's $t$ test, Table 1). However, the intervals from the decrease in photoperiod were not significantly different $(P>0.05$, Table 1$)$.

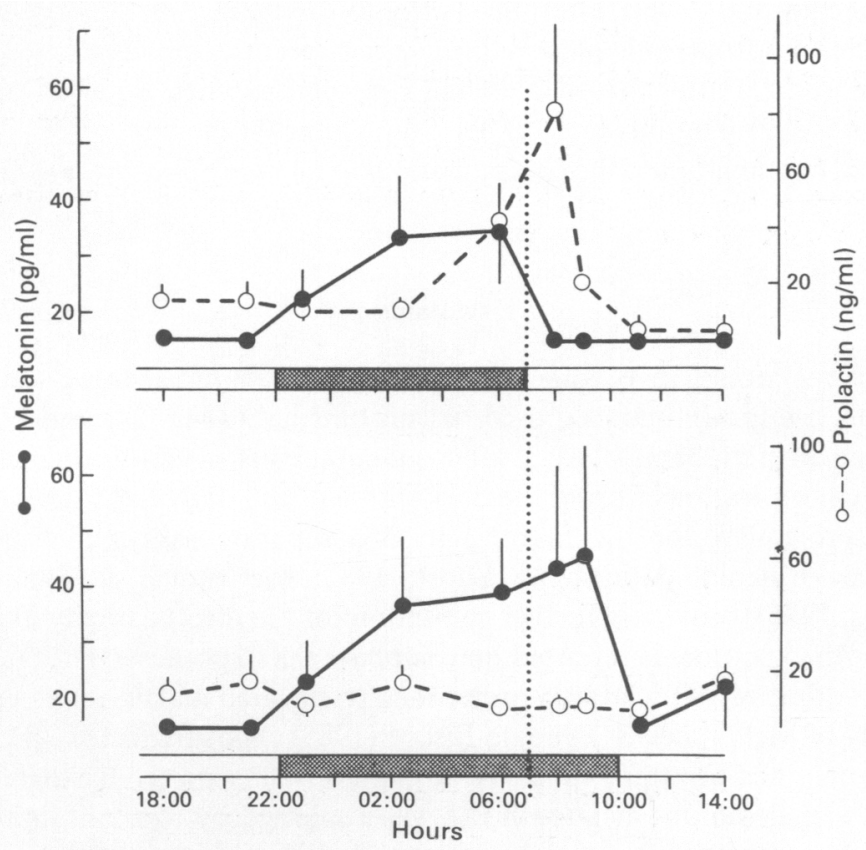

Fig. 4. Plasma melatonin ( ) and prolactin $(\mathrm{O}-\mathrm{O})$ concentrations (mean \pm s.e.m.) of tammars in Exp. 2 maintained under a photoperiod of 15L:9D (a) and 5 days after a change to 12L:12D (b). The stippled bars indicate the dark phases of each photoperiod. The dotted vertical line indicates the time of lights on during 15L:9D.

\section{Experiment 2}

All 6 tammars gave birth $31.2 \pm 1.0$ days after the photoperiod change from 15L:9D to 12L:12D (Fig. 2b). This interval is not significantly different $(P>0.05)$ from that reported by McConnell \& Tyndale-Biscoe (1985) for tammars that had experienced the same decrease in daylength, but by extending the dark phase in the evening rather than in the morning.

\section{Hormone concentrations in peripheral plasma}

Experiment 1. Exposure to $24 \mathrm{~L}: 0 \mathrm{D}$ abolished the nocturnal melatonin rise. In the melatonininjected group a pulse of melatonin at a physiological concentration $(46.4 \pm 4.78 \mathrm{pg} / \mathrm{ml}$, mean \pm s.e.m.) was detected $1.5 \mathrm{~h}$ after the injection at $21: 00 \mathrm{~h}$ (Fig. 3b) but this was absent in the 
oil-injected tammars (Fig. 3a). After the change from $24 \mathrm{~L}: 0 \mathrm{D}$ to $15 \mathrm{~L}: 9 \mathrm{D}$, increased melatonin concentrations coincident with the dark phase were detected in both groups $(56.4 \pm 8.5 \mathrm{pg} / \mathrm{ml}$ to $83.6 \pm 14.7 \mathrm{pg} / \mathrm{ml})$. At $21: 00 \mathrm{~h}$ melatonin was still detectable in the melatonin-injected group $(30.5 \pm 6.4 \mathrm{pg} / \mathrm{ml}$, but was undetectable $(<16 \mathrm{pg} / \mathrm{ml})$ in the oil-injected group (Fig. $3 \mathrm{c}$ ).

Experiment 2. Plasma melatonin concentrations were elevated during the dark phases of each photoperiod, ranging from $22.0 \pm 5 \cdot 2$ to $45 \cdot 7 \pm 19 \cdot 7 \mathrm{pg} / \mathrm{ml}$ (Fig. 4). Under 15L:9D the melatonin concentrations had declined to undetectable levels $(<16 \mathrm{pg} / \mathrm{ml})$ within $1 \mathrm{~h}(08: 00 \mathrm{~h})$ of lights on in all 6 tammars and remained so (Fig. $4 \mathrm{a}$ ). By 5 days after the change to $12 \mathrm{~L}: 12 \mathrm{D}$, however, the concentrations at $08: 00 \mathrm{~h}$ and $09: 00 \mathrm{~h}$ remained elevated $(43.3 \pm 18.6$ and $45.7 \pm 19.7 \mathrm{pg} / \mathrm{ml})$, coincident with the extended dark phase, before declining to undetectable values at 11:00 $\mathrm{h}, 1 \mathrm{~h}$ after lights on (Fig. 4b). There was no change in the amplitude of the nocturnal melatonin rise or its phase, relative to the light/dark cycle, after the change to $12 \mathrm{~L}: 12 \mathrm{D}$.

Under the 15L:9D photoperiod, plasma prolactin concentrations remained below $20 \mathrm{ng} / \mathrm{ml}$, except at $1 \mathrm{~h}$ before and $1 \mathrm{~h}$ after the onset of the light phase, when a pulse was detected, which reached a peak of $81.5 \pm 31.0 \mathrm{ng} / \mathrm{ml}$ (Fig. $4 \mathrm{a}$ ). By 5 days after the change to $12 \mathrm{~L}: 12 \mathrm{D}$, however, this pulse was absent in all 6 tammars and the concentrations at all time points were $<20 \mathrm{ng} / \mathrm{ml}$ (Fig. $4 \mathrm{~b}$ ).

\section{Discussion}

The direct assay of melatonin in plasma was validated by demonstrating the abolition of the nocturnal melatonin rise in tammars exposed to constant light (Fig. 3a) and by the detection of a pulse of melatonin in peripheral plasma after subcutaneous injection of melatonin (Fig. $3 \mathrm{~b}$ ). Highest melatonin concentrations during the dark phase of the daily light/dark cycle were similar to those reported previously for the tammar in two separate assays that utilized extraction procedures (Renfree, Lincoln, Almeida \& Short, 1981; McConnell \& Tyndale-Biscoe, 1985; McConnell \& Hinds, 1985), providing further validation for the direct assay method.

The results of both experiments reported here support the hypothesis that tammars respond to a change in the total duration of melatonin rather than to elevated melatonin at a particular time of the day. In the study of McConnell \& Tyndale-Biscoe (1985) exposure to 15L:9D alone was inhibitory but tammars responded promptly in this photoperiod when also given exogenous melatonin at 19:30 h. In Exp. 1 the endogenous melatonin rise was abolished by constant light and, although a rise in melatonin was reinstated after the change to $15 \mathrm{~L}: 9 \mathrm{D}$, it alone cannot have been the signal for reactivation as it did not lead to reactivation in the control group. In the melatonin-treated tammars, however, the injections resulted in a pulse of melatonin before the onset of the dark phase (Fig. 3c), and although the tammars had been injected for 15 days before exposure to 15L:9D (Fig. $3 b$ ), they had failed to respond to this treatment alone. Therefore, exposure to melatonin during the period $2.5 \mathrm{~h}$ before dark is not by itself a sufficient stimulus to initiate reactivation and the sensitive period hypothesis is not sustained. Similarly, in Exp. 2 an extension of the dark phase by $3 \mathrm{~h}$ in the morning was as effective for reactivation in the tammars as was an extension of $3 \mathrm{~h}$ in the evening (McConnell \& Tyndale-Biscoe, 1985), because in both experiments birth occurred 30-33 days later. The response in the melatonin profile was also similar after each photoperiod change, so it is probable that the same component of the melatonin profile transduced the photoperiodic signal. As there was no change in the amplitude or the phase of the melatonin rise in either experiment the stimulatory component was probably the increase in duration of elevated melatonin during the longer dark phase.

The results of the present study also support the suggestion of McConnell \& Tyndale-Biscoe (1985) that it is not duration alone but a change in the melatonin profile, relative to a previously experienced profile, that provides the stimulatory signal for the tammar. If the pulse of melatonin, resulting from the melatonin injection in Exp. 1, was interpreted by the tammars as an ultra-short 
night, then the longer endogenous profile of 15L:9D which followed may have been interpreted as a change in the duration of the melatonin profile. Conversely, the control group in Exp. 1 may not have been able to detect the new 15L:9D profile as a change because they had no reference point, i.e. an exogenous melatonin pulse, with which to make a comparison. However, another interpretation of these results is that the tammar responds to a minimum duration of elevated melatonin as has been demonstrated for the Djungarian hamster. In pinealectomized hamsters subcutaneous infusions of melatonin induced testicular regression only if the duration of infusion exceeded a critical length of $8 \mathrm{~h}$ (Carter \& Goldman, 1983a). Similarly, in the tammar, exposure to melatonin for a continuous period longer than $9 \mathrm{~h}$ per day may be required to elicit reactivation, since tammars have only been observed to respond to an increase in the dark phase from 15L:9D to 13L:11D, or from 15L:9D to $12 \mathrm{~L}: 12 \mathrm{D}$, or from melatonin injections $2.5 \mathrm{~h}$ before dark given to tammars maintained in 15L:9D. Duration of elevated melatonin alone is not, however, a sufficient stimulus to reactivation since tammars do not reactivate at or soon after the winter solstice when the duration of elevated melatonin exceeds $9 \mathrm{~h}$ (McConnell \& Tyndale-Biscoe, 1985). While a refractory period after the winter solstice cannot be ruled out, an alternative hypothesis is that such tammars fail to reactivate because they no longer perceive an increase in the duration of elevated melatonin at this time.

We therefore conclude that reactivation in the tammar, in response to decreased photoperiod, is effected by a change in duration of the nocturnal melatonin rise to more than $9 \mathrm{~h}$. This conclusion may also explain how continuously available melatonin mimics the effects of decreased daylength; subcutaneous implants of melatonin induced reactivation in seasonally quiescent tammars (Renfree \& Short, 1984) and Bennett's wallabies, M. rufogriseus (Loudon, Curlewis \& English, 1985) within 3 and 12 days respectively. In both studies the wallabies were implanted during long daylengths, about 1 month before the summer solstice, when they could be expected to have a short period of melatonin secretion coincident with the short nights. Implants raise the circulating concentrations of melatonin during the daytime (Kennaway, Gilmore \& Seamark, 1982b; Loudon et $a l ., 1985)$ and so in combination with the endogenous rise this could be interpreted as an increase in duration of the melatonin profile.

In the tammar the stimulatory effects of melatonin on the CL may be due to its effects on prolactin release by the pituitary, as hypophysectomy will also reactivate the CL (Hearn, 1973, 1974) and daily injections of ovine prolactin after hypophysectomy will delay reactivation for the duration of the treatment (Tyndale-Biscoe \& Hawkins, 1977). Although a decrease in daylength from 15L:9D to 12L:12D reduced peripheral plasma prolactin concentrations to basal levels within 14 days (Hinds \& den Ottolander, 1983), its importance in reactivation is unclear, since the CL is already reactivated within 9 days of the photoperiod change, and prolactin levels remained unchanged in tammars reactivated during exposure to gradual decreasing photoperiod or 9L:15D (Hinds \& den Ottolander, 1983). In Exp. 2 the circadian plasma prolactin profile was measured at the same time as melatonin before and after the decrease in daylength from 15L:9D to 12L:12D. Before the change there was a distinct short pulse of prolactin beginning $1 \mathrm{~h}$ before lights on, but 5 days after the change to $12 \mathrm{~L}: 12 \mathrm{D}$, it was absent. As the events leading to reactivation of the CL must occur within about 6 days of the decrease in daylength, abolition of this dawn prolactin pulse by Day 5 may be associated with reactivation. This may account for the paradox that prolactin injections given after removal of the pouch young or after hypophysectomy inhibited reactivation, even though basal concentrations in intact animals showed no change. However, further work will be required to determine the importance of the transient pulse of prolactin in the inhibition of the CL.

We thank Mr J. Wright, Mr R. Leckie and Dr T. P. Fletcher for assistance in handling the animals and taking blood samples: and Dr D. J. Kennaway for the gift of anti-melatonin antiserum. This work was supported in part by a grant from the M. A. Ingram Trust, Melbourne, Australia. 


\section{References}

Berger, P.J. (1966) Eleven-month 'embryonic diapause' in a marsupial. Nature, Lond. 211, 435-436.

Bittman, E.L. \& Karsch, F.J. (1984) Nightly duration of pineal secretion determines the reproductive response to inhibitory daylength in the ewe. Biol. Reprod. 30, 585-593.

Bittman, E.L., Dempsey, R.J. \& Karsch, F.J. (1983) Pineal melatonin secretion drives the reproductive response to daylength in the ewe. Endocrinology 113, 2276-2283.

Carter, D.S. \& Goldman, B.D. (1983a) Antigonadal effects of timed melatonin infusion in pinealectomized male Djungarian hamsters (Phodopus sungorus sungorus): duration is the critical parameter. Endocrinology 113, 1261-1267.

Carter, D.S. \& Goldman, B.D. (1983b) Progonadal role of the pineal in the Djungarian hamster (Phodopus sungorus sungorus): mediation by melatonin. Endocrinology $113,1268-1273$.

Goldman, B.D. \& Darrow, J.M. (1983) The pineal gland and mammalian photoperiodism. Neuroendocr. 37 386-396.

Goldman, B.D., Darrow, J.M. \& Yogev, L. (1984) Effects of timed melatonin infusions on reproductive development in the Djungarian hamster (Phodopus sungorus). Endocrinology 114, 2074-2083.

Hearn, J.P. (1973) Pituitary inhibition of pregnancy. Nature, Lond. 241, 207-208.

Hearn, J.P. (1974) The pituitary gland and implantation in the tammar wallaby, Macropus eugenii. J. Reprod. Fert. 39, 235-241.

Hinds, L.A. \& den Ottolander, R.C. (1983) Effect of changing photoperiod on peripheral plasma prolactin and progesterone concentrations in the tammar wallaby (Macropus eugenii). J. Reprod. Fert. 69 , 631-639.

Hinds, L.A. \& Tyndale-Biscoe, C.H. (1982) Prolactin in the marsupial Macropus eugenii, during the estrous cycle, pregnancy and lactation. Biol. Reprod. 26, 391-398.

Karsch, F.J., Bittman, E.L., Foster, D.L., Goodman, R.L., Legan, S.J. \& Robinson, J.E. (1984) Neuroendocrine basis of seasonal reproduction. Recent Progr. Horm. Res. 40, 185-232.

Kennaway, D.J., Gilmore, T.A. \& Seamark, R.F. (1982a) Effect of melatonin feeding on serum prolactin and gonadotropin levels and the onset of seasonal estrous cyclicity in sheep. Endocrinology 101, 119-127.

Kennaway, D.J., Gilmore, T.A. \& Seamark, R.F. (1982b) Effects of melatonin implants on the circadian rhythm of plasma melatonin and prolactin in sheep. Endocrinology 110, 2186-2188.

Lincoln, G.A., Almeida, O.F.X. \& Arendt, J. (1981) Role of melatonin and circadian rhythms in seasonal reproduction in rams. $J$. Reprod. Fert., Suppl. 30, $23-31$.

Loudon, A.S.I., Curlewis, J.D. \& English, J. (1985) The effect of melatonin on the seasonal embryonic diapause of the Bennett's wallaby (Macropus rufogriseus rufogriseus). J. Zool., Lond. 206, 35-39.

Margolis, D.J. \& Lynch, G.R. (1981) Effects of daily melatonin injections on female reproduction in the white-footed mouse, Peromyscus leucopus. Gen. comp. Endocr. 44, 530-537.
McConnell, S.J. \& Hinds, L.A. (1985) Effect of pinealectomy on plasma melatonin, prolactin and progesterone concentrations during seasonal reproductive quiescence in the tammar, Macropus eugenii. $J$. Reprod. Fert. 75, 433-440.

McConnell, S.J. \& Tyndale-Biscoe, C.H. (1985) Response in peripheral plasma melatonin to photoperiod change and the effects of exogenous melatonin on seasonal quiescence in the tammar, Macropus eugenii. J. Reprod. Fert. 73, 529-538.

McNeilly, A.S. \& Friesen, H.G. (1978) Heterologous radioimmunoassay for rabbit prolactin. Endocrinology 102, 1539-1547.

Merchant, J.C. (1979) The effect of pregnancy on the interval between one oestrus and the next in the tammar wallaby, Macropus eugenii. J. Reprod. Fert. 56, $459-463$.

Renfree, M.B., Lincoln, D.W., Almeida, O.F.X. \& Short, R.V. (1981) Abolition of seasonal embryonic diapause in a wallaby by pineal denervation. Nature, Lond. 293, 138-139.

Renfree, M.B. \& Short, R.V. (1984) Seasonal reproduction in marsupials. In Endocrinology 1984, pp. 789-792. Eds F. Labrie \& L. Proulx. Excerpta Medica, Amsterdam.

Sadleir, R.M.F.S. \& Tyndale-Biscoe, C.H. (1977) Photoperiod and the termination of embryonic diapause in the marsupial Macropus eugenii. Biol. Reprod. 16, $605-608$.

Sernia, C. \& Tyndale-Biscoe, C.H. (1979) Prolactin receptors in the mammary gland, corpus luteum and other tissues of the tammar wallaby, Macropus eugenii. J. Endocr. 83, 79-89.

Stetson, M.H. \& Tay, D.E. (1983) Time course of sensitivity of golden hamsters to melatonin injections throughout the day. Biol. Reprod. 29, 432-438.

Tamarkin, L., Westrom, W.K., Hamill, A.I. \& Goldman, B.D. (1976) Effect of melatonin on the reproductive systems of male and female Syrian hamsters: a diurnal rhythm in sensitivity to melatonin. Endocrinology 99, 1534-1541.

Tamarkin, L., Baird, C.J. \& Almeida, O.F.X. (1985) Melatonin: a coordinating signal for mammalian reproduction? Science, $N . Y .227,714-722$.

Tyndale-Biscoe, C.H. \& Hawkins, J. (1977) The corpora lutea of marsupials: Aspects of function and control. In Reproduction and Evolution, pp. 245-252. Eds J. H. Calaby \& C. H. Tyndale-Biscoe. Australian Academy of Science, Canberra.

Tyndale-Biscoe, C.H. \& Hinds, L.A. (1984) Seasonal patterns of circulating progesterone and prolactin and response to bromocriptine in the female tammar Macropus eugenii. Gen. comp. Endocr. 53, 58-68.

Webley, G.E., Mehl, H. \& Willey, K.P. (1985) Validation of a sensitive direct assay for melatonin for investigation of circadian rhythms in different species. $J$. Endocr. 106, 387-394.

Yellon, S.M., Bittman, E.L., Lehman, M.N., Olster, D.H., Robinson, J.E. \& Karsch, F.J. (1985) Importance of duration of nocturnal melatonin secretion in determining the reproductive response to inductive photoperiod in the ewe. Biol. Reprod. 32, 523-529.

Received 2 December 1985 